use of sensitive assays of digoxin in body fluids. ${ }^{11}$ This knowledge has recently been reviewed in detail by Smith and Haber. ${ }^{12}$ Digoxin in serum is only $23 \%$ protein bound and is excreted primarily in the urine in unchanged form or as small amounts of metabolites which are both cardioactive and immunoreactive. Urinary excretion is directly proportional to the glomerular filtration rate, and serum levels in the elimination phase decline exponentially with an average serum half time of 36 hours in patients with normal renal function. Daily maintenance treatment without a loading dose results in a steady-state plateau concentration after four or five half lives or about seven days in patients with normal renal function. ${ }^{13}$ Impairment of renal function is associated with higher serum digoxin concentrations at any dose level.

Clearly, therefore, consistent differences in glomerular filtration rate in patients with thyroid disease, of the order observed in our patients, would influence comparative serum digoxin concentrations. In a recent review of renal function in patients with thyroid disease ${ }^{14}$ inulin clearance was found to be raised $(145.5 \pm 5.6 \mathrm{ml} / \mathrm{min}$ in 36 hyperthyroid patients reported by seven groups of workers), and in 17 hypothyroid patients G.F.R. fell to $71 \pm 4.3 \mathrm{ml} / \mathrm{min}$ and then rose towards normal in six out of seven patients who received replacement therapy. In view of the close correlation between digoxin and creatinine clearance the finding of a short digoxin half time and lower serum concentrations of digoxin in the hyperthyroid patients was not unexpected. A similar interpretation is implicit in Doherty's data; mean digoxin clearance was $158 \mathrm{ml} / \mathrm{min}$ and $83 \mathrm{ml} / \mathrm{min}$ in hyperthyroid and hypothyroid subjects respectively, ${ }^{5} \mathrm{Un}$ doubtedly a difference in tissue distribution space for digoxin exists in patients with changed thyroid status, but this difference is not relevant to the serum concentrations after achievement of a steady-state plateau in clinical therapeutics.

Serum digoxin concentrations in hyperthyroid subjects could also be low secondary to decreased absorption or increased metabolism or faecal excretion of the drug, factors which might explain our discrepant findings. The demonstration of a relative increase in cumulative urinary digoxin excretion in two hyper- thyroid patients despite low serum concentrations argues against an important role for these alternative routes of metabolism or excretion.

A rapid ventricular response to atrial fibrillation refractory to digitalis treatment is common in hyperthyroidism. Chamberlain's finding of a correlation between slowing of the ventricular rate in patients with atrial fibrillation and serum digoxin levels ${ }^{15}$ suggested that this apparent refractoriness may be partly due to the lower serum concentration in the hyperthyroid patient. Many clinical studies have established the correlation between serum digoxin levels and therapeutic or toxic effects of the drug, and our findings indicate that ideal digitalization of patients with altered thyroid function requires measurement of both serum digoxin and glomerular filtration rate.

We thank Messrs. B. White and M. B. John and the technical staff of the department of nuclear medicine who were involved in the development and use of the digoxin radioimmunoassay.

\section{References}

1 Buccino, R. A., et al., fournal of Clinical Investigation, 1967, 46, 1669.

2 Peacock, W. F., and Moran, N. C., Proceedings of the Society for Experimental Biology and Medicine, 1963, 113, 526.

${ }^{3}$ Morrow, D. H., Gaffney, T. E., and Braunwald, E., Fournal of Pharmacology and Experimental Therapeutics, 1963, 140, 324

4 Frye, R. L., and Braunwald, E., Circulation, 1961, 23, 376.

5 Doherty, J. E., and Perkins, W. H., Annals of Internal Medicine, 1966, 64, 489 .

${ }^{6}$ Eickenbush, W., et al.,Klinische Wochenschrift, 1970, 48, 270.

${ }^{7}$ Herbert, V., et al., Clinical Medicine, 1965, 66, 814.

${ }^{8}$ Smith, T. W., Butler, V. P., and Haber, E., New England fournal of Medicine, 1969, 281, 1212.

${ }^{9}$ Doolan, P. D., Alpen, E. L., and Theil, G. B., American fournal of Medicine, 1962, 32, 65.

10 Doherty, J. E., American fournal of Medical Science, 1968, 255, 382.

${ }_{11}$ Butler, V. P., Progress in Cardiovascular Disease, 1972, 14, 571.

12 Smith, T. W., and Haber, E., New England Fournal of Medicine, 1973, $289,1063$.

13 Marcus, F. L., et al., Circulation, 1966, 34, 865.

${ }^{14}$ Bradley, S. E., et al., Kidney International, 1974, 6, 346

${ }^{15}$ Chamberlain, D. A., et al., British Medical fournal, 1970, 3, 429.

\title{
Isolation and Characterization of an Aetiological Agent in Whipple's Disease
}

\author{
R. L. CLANCY, W. A. F. TOMKINS, T. J. MUCKLE, H. RICHARDSON, W. E. RAWLS
}

British Medical fournal, 1975, 3, 568-570

\section{Summary}

A cell wall deficient form of an $\alpha$-haemolytic streptococcus was grown from a prolonged monolayer cell culture of a lymph node taken from a patient with

Department of Medicine, McMaster University, Hamilton, Ontario, Canada

R. L. CLANCY, F.R.A.C.P., PH.D., Assistant Professor

Department of Pathology, McMaster University, Hamilton, Ontario, Canada

W. A. F. TOMKINS PH.D., Associate Professor

T. J. MUCKLE, M.D., F.R.C.P., Associate Professor

H. RICHARDSON, M.D., F.R.C.P., Associate Professor

W. E. RAWLS, M.D., Professor
Whipple's disease. Serological cross reactivity was shown between the organism and the material within Whipple's disease macrophages positive for diastase-resistant periodic acid-Schiff (D./P.A.S.). In vitro studies characterized the organism as a facultative intracellular parasite which caused the accumulation within cells of D./P.A.S.-positive material. These results suggest that a pathogenic bacterium is the essential aetiological agen $t$ and that the culture of Whipple's disease tissues in hypertonic media may have practical value.

\section{Introduction}

Whipple's disease is a systemic illness characterized morphologically by the presence of macrophages stained by diastaseresistant periodic acid-Schiff (D./P.A.S.) with maximum involvement occurring in the lamina propria of the proximal small intestine.' The aetiology remains an enigma. Indirect evidence strongly suggests the presence of an infectious agent, ${ }^{2}$ 
but no organism has been clearly related to the pathogenesis of this disorder. We report here the isolation of a cell wall deficient (C.W.D.) bacterium from a prolonged lymph node culture with features that strongly suggested that this organism was an aetiological agent.

\section{Patient and Methods}

A 40-year-old woman presented with a five-year history of progressive lassitude, weight loss, skin pigmentation, pedal oedema, and arthralgia. Examination showed lymphadenopathy. Abnormal findings included faecal fat excretion of $21 \mathrm{~g}$ in three days (normal $<15 \mathrm{~g}$ ), a proteinlosing gastroenteropathy ( $5 \%$ faecal loss of ${ }^{51} \mathrm{Cr}-\mathrm{Cl}_{3}$; normal $<1 \%$ ), and an erythrocyte sedimentation rate of $100 \mathrm{~mm}$ in one hour. A small-bowel biopsy showed typical macroscopic and microscopic features of Whipple's disease, ${ }_{3}$ including distention of villi by macrophages loaded with D./P.A.S.-positive material, which on electron microscopy were shown to contain numerous bacillary forms (fig. 1).

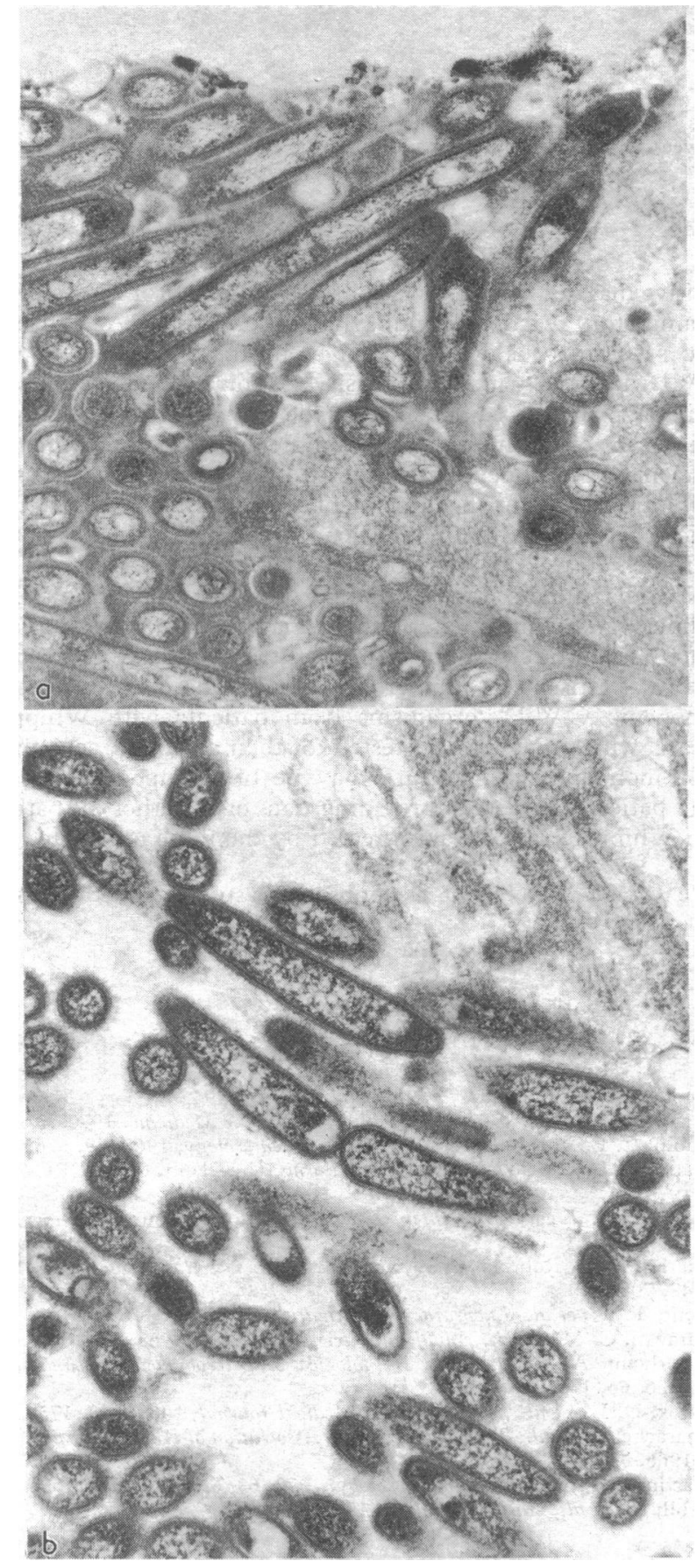

FIG. 1-Electronmicrographs of bacteria (a) in jejunum and (b) in six-week lymph node culture. ( $\times 29455$.
Similar histological and ultramicroscopic abnormalities were detected in a lymph node. Treatment with tetracycline ( $1 \mathrm{~g} /$ day) induced a rapid clinical improvement, and repeat small-bowel biopsy at three months showed a reduction in the amount of intracellular D./P.A.S.positive material and improved villous structure.

An axillary lymph node was minced and grown as monolayer cultures in Eagle's minimal essential medium supplemented with $10 \%$ heat-inactivated fetal calf serum, with and without added antibiotics (penicillin $100 \mathrm{U} / \mathrm{ml}$, streptomycin $100 \mathrm{mg} / \mathrm{l}$ ). Subcultures prepared at six weeks were stained with the D./P.A.S. technique. These cultures were also examined by electron microscopy. Supernatants taken from the lymph node culture at six weeks were transferred to human colon fibroblast cultures. After four hour' incubation the inoculum was removed and the monolayers were washed with medium, incubated for a further four days, and stained with D./P.A.S.

Standard microbiological methods were used to isolate and characterize bacteria and C.W.D. forms. ${ }^{4}$ Bacteria were inoculated on to cultures of human colon fibroblasts and cells stained with D./P.A.S. at four days.

Jejunal and lymph node tissues were examined by indirect immunofluorescence ${ }^{5}$ with sera from the patient and from eight normal people both before and after absorption with the cultured bacteria. After dilution 1/10 with buffered saline serum was absorbed with an equal volume of killed packed organisms for three hours at $37^{\circ} \mathrm{C}$ and then overnight at $4^{\circ} \mathrm{C}$. Fluorescein-conjugated antisera to human IgA, IgG, and IgM were raised in rabbit (obtained from Behringwerke, Marburg-Lahn, West Germany), with azovan (Evans) blue used as counterstain.

\section{Results}

Isolation of Organism.-Primary cultures of blood, jejunal aspirate, bone marrow, and lymph node yielded no growth in normal or hypertonic culture media. Culture of the jejunal biopsy specimen yielded no growth in normal media, but a C.W.D. form grew out in hypertonic media. The morphology and staining and growth characteristics were identical to those of the organism grown from the lymph node culture. Cell monolayers grown from the lymph node developed discrete areas of rounded cells at four weeks. No bacterial contaminants grew in thioglycolate broth. Focal areas of cellular degeneration developed by six weeks; these were more pronounced in the cultures without antibiotics. Cell culture supernatants containing cells and debris taken at six weeks yielded no growth in normal media, but a C.W.D. form grew in hypertonic sucrose medium. This organism failed to grow when subcultured to normal media, but on subculture to hypertonic solid media and then to normal media grew out as typical microbial colonies which were $\alpha$-haemolytic on blood agar. This organism was a Gram-positive coccus identified, on biochemical criteria, as Streptococcus dysgalactiae.

Characteristics of Organism.- Monolayer cells taken from the lymph node culture at the time the C.W.D. form was isolated showed cells distended with D./P.A.S.-positive material (fig. 2), which on electron microscopy were shown to contain bacteria indistinguishable from those found in the gut mucosa (fig. 1). These changes were much more pronounced in cultures without antibiotics. Negative controls included a variety of human and animal cell lines. Inoculation of the lymph node culture on to monolayers of human colon fibroblasts induced the accumulation of D./P.A.S.-positive material within the cultured cells. The isolated organism was inoculated on to monolayers of human fibroblasts. No growth was detected in the supernatant, but the bacteria grew within cells and stained positive with D./P.A.S. (fig. 2). The C.W.D. organism was sensitive to tetracycline in vitro.

Serological Characterization of Organism.-Indirect immunofluorescence showed that the patient's serum contained antibody against the material within Whipple's disease macrophages, at titres of $1 / 64-1 / 80$ in the IgA class and less than $1 / 4$ in the $\operatorname{IgG}$ and $\operatorname{IgM}$ classes. Normal control sera were weakly positive at titres of up to $1 / 16$. Absorption of the patient's serum with the isolated bacteria completely removed antibody activity, while the unabsorbed control retained a titre of $1 / 80$.

\section{Discussion}

A diagnosis of Whipple's disease in this patient was confirmed by the consistent clinical features and the characteristic pathological findings on jejunal biopsy. ${ }^{3}$ The ultramicroscopic demonstration of bacillary forms in tissues together with the 

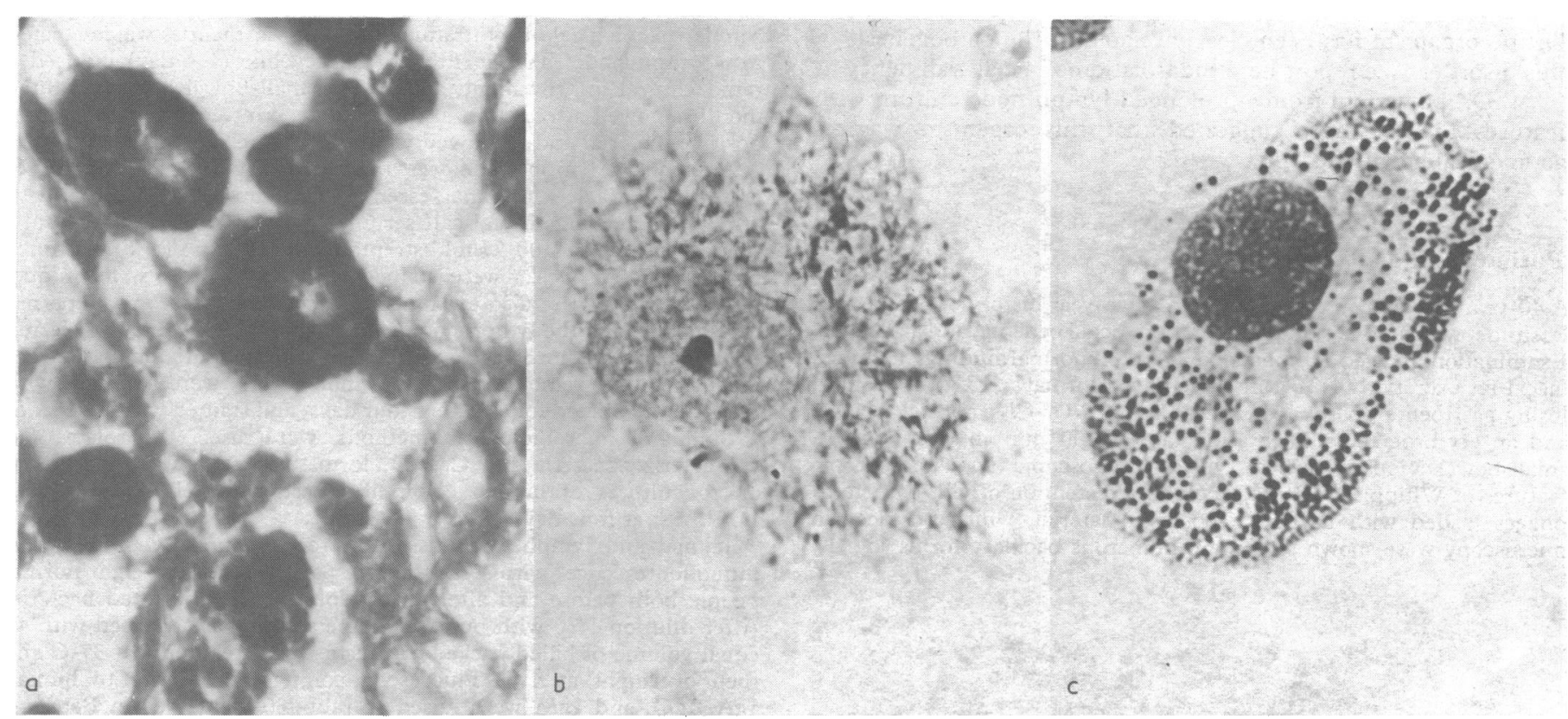

FIG 2-D./P.A.S.-positive material within cells: (a) jejunal biopsy specimen; (b) six-week lymph node culture; and (c) fibroblast after inoculation of bacteria isolated from Whipple's disease lymph node. $(\times 1002$.

response to antibiotics in our patient, as well as others with Whipple's disease, ${ }^{2}$ provide strong indirect evidence that bacteria contribute to the pathogenesis of this disease. The previous failure to isolate and characterize a microbial agent, ${ }^{26}$ however, has left unanswered the question of whether the primary aetiological factor in Whipple's disease is an unusual micro-organism or an impaired mechanism of host resistance. Various bacteria have been grown from tissues of patients with Whipple's disease, ${ }^{7-9}$ but contamination has not usually been excluded, the tendency to favour intracellular growth has not been examined, and the specificity of the host's immune response has not been de fined. We have isolated a pure growth of bacteria from a lymph node culture and reproduced in vitro the essential intracellular pathological character of Whipple's disease with this organism.

The organism isolated from the lymph node culture finally grew out as an $\alpha$-haemolytic streptococcus. Its growth characteristics and the variation of shape, size, and staining were characteristic of a C.W.D. bacterial form. ${ }^{4}$ Isolation from prolonged cuiture of lymph node cells and growth of the same organism from an intestinal biopsy specimen makes it unlikely that this organism was a contaminant. An $\alpha$-haemolytic streptococcus has been isolated from several patients with Whipple's disease, ${ }^{7}$ on two occasions as C.W.D. form. ${ }^{10}{ }^{11}$ Only one study ${ }^{11}$ excluded contamination, but it failed to identify the organism as an aetiological agent. In our study the bacteria was grown from cells which both stained with P.A.S. and contained bacteria detected with the electron microscope. Serological identity between the intracellular material and the isolated bacteria was shown by the complete absorption with the bacteria of antibody reacting with the D./P.A.S.-positive material. These observations strongly suggest that the isolated $\alpha$-haemolytic streptococcus was identical to the intracellular bacteria in our patient.

The essential pathological process in Whipple's disease is the accumulation of D./P.A.S.-positive material within macrophages. ${ }^{2}$ The abnormal bacteria grown from Whipple's disease tissues were characterized by facultative intracellular growth in vitro with the parasitized cells accumulating D./P.A.S.positive material. Furthermore, the parenteral injection of this C.W.D. organism into a rabbit caused systemic disease characterized pathologically by the accumulation of D./P.A.S.- positive material within macrophages, with little or no associated inflammatory reaction (unpublished observations). An $\alpha$-haemolytic streptococcus was isolated from these lesions. Thus, a C.W.D. bacteria with a propensity for intracellular growth was probably primarily responsible for the pathogenesis of Whipple's disease in our patient. The complete return to normal of deficient $\mathrm{T}$-lymphocyte numbers and function after successful antibiotic treatment in our patient (unpublished observations) indicates that the immunodeficiency described in patients with Whipple's disease ${ }^{1213}$ may be secondary to the disease.

Not all patients with Whipple's disease respond to tetracycline, ${ }^{11}$ and clinical deterioration may occur before an appropriate antibiotic is found through trial and error. Routine culture of a tissue into hypertonic sucrose may allow growth of pathogenic C.W.D. organisms from patients with Whipple's disease, which may then be tested for their antibiotic sensitivity. Prior monolayer cell culture may be of therapeutic value in some patients as well as providing data on whether all patients with Whipple's disease are infected by the same organism.

We thank Dr. S. N. Banerjee for help with studies related to passage of the bacteria.

\section{References}

${ }^{1}$ Sieracki, J. C., Archives of Pathology, 1958, 66, 494.

2 Maizel, H., Ruffin, J. M., and Dobbins, W. O., Medicine, 1970, 49, 175

${ }^{3}$ Rubin, C. E., and Dobbins, W. O., Gastroenterology, 1965, 49, 676.

${ }^{4}$ Mattman, L. H., Cell Wall Deficient Forms. Cleveland, Ohio, CRC Press, 1974.

${ }^{5}$ Nairn, R. C., Fluorescent Protein Tracing, 3rd edn. Edinburgh, Livingstone, 1969.

${ }^{6}$ Sherris, J. C., Roberts, C. E., and Porus, R. L., Gastroenterology, 1965, 48, 708 .

${ }^{7}$ Kent, T. H., et al., Laboratory Investigation, 1963, 12, 1163.

8 Caravati, C. M., et al., Annals of Internal Medicine, 1963, 58, 166.

${ }^{9}$ Kjaerheim, A., et al., Acta Pathologica et Microbiologica Scandinavia, $1966,66,135$.

10 Knox, D. L., et al., fohns Hopkins Medical fournal, 1968, 123, 175

${ }^{11}$ Charache, P., et al., Transactions of the Association of American Physicians, $1966,79,399$.

${ }^{12}$ Martin, F. F., et al., Gastroenterology, 1970, 63, 6.

${ }_{13}$ Groll, A., et al., Gastroenterology, 1972, 63, 943 . 